\title{
Junctional Ectopic Tachycardia
}

National Cancer Institute

\section{Source}

National Cancer Institute. Junctional Ectopic Tachycardia. NCI Thesaurus. Code C111646.

A tachycardia originating in or adjacent to the AV junction. 